\title{
Through-the-thickness response of hybrid 2D and 3D woven composites
}

\author{
Mark Pankow* \\ North Carolina State University, Raleigh, NC,27695, USA \\ Chian-Fong Yen ${ }^{\dagger}$ \\ ARMY Research Laboratory, Aberdeen Proving Ground, MD, 21005, USA \\ Brian Justusson and Anthony M. Waas ${ }^{\ddagger}$ \\ Aerospace Engineering, University of Michigan, Ann Arbor, MI, 48109
}

\begin{abstract}
3D woven materials are investigated for their through-the-thickness response. In this study, hybrid 3D woven composites, consisting of multiple fiber tows (carbon, glass and kevlar) have been investigated. Quasi-static tests were performed to determine the effective through-the-thickness response when subjected to confined compression. Confined compression was chosen because it shows similar failure modes to those seen under dynamic loading. The results presented in this paper show a correlation to changes in strength based on hybridization, however some of the observed results were not as expected.
\end{abstract}

\section{Introduction}

Composite materials used in impact prone applications have created a need to understand the failure mechanisms associated with elevated rates of loading. Typical high strain rate testing includes the use of compressive Hopkinson bar setups. 2D in-plane woven material was investigated previously and found to form failure bands of high shear at angles to the loading direction under high rates of loading. ${ }^{1,2}$ Studies were further extended to $3 \mathrm{D}$ woven composites ${ }^{3}$ which showed similar shear band failure modes at high rates. It was also shown that failure occurred differently in these materials with diffused microcracking at low rates and shear failure at high rates. ${ }^{4}$ Elevated rate tests show that a shear band typically formed in the material causing shear failure of the fiber tows. The angle of the band associated with shear failure has also been investigated previously to determine the effective failure envelope that can be formed. ${ }^{5}$

Due to the difficulty and limited information that can accurately be obtained from high rate testing, a quasi-static approach to determine similar failure mechanisms would provide a good approach for determining properties so that one can effectively design the 3D textile material architecture. One such proposed method has been the punch shear test. The test method works by pushing a steel punch through a composite specimen with supports on the back side to prevent bending from occurring. ${ }^{6}$ These tests provide similar characteristics to those found in ballistic testing with shear deformation occurring in the specimen. The test results provide useful insight, however some of the information obtained from the tests are difficult to interpret or do not correlate well with mechanical models. Additionally, the stress concentration from the contact must be accounted for. The key point from all of these tests was that the confined compression response had similar failure mechanisms to high rate response due to the inability of the material to expand due to Poisson's effect.

Therefore confined compression tests will help to identify key failure mechanisms associated with 3D woven composite materials (3DWC) and guide the development of predictive models for failure at elevated rates. In this paper a new method to perform the confined compression test will be investigated. Different

\footnotetext{
*Assistant Professor, Mechanical and Aerospace Engineering, North Carolina State University, Raleigh, NC, 27695

${ }^{\dagger}$ Army Research Laboratory, Aberdeen Proving Ground, MD, 21005

${ }_{\ddagger}^{\ddagger}$ Felix Pawlowski Collegiate Professor, Aerospace Engineering, University of Michigan, Ann Arbor, MI, 48109. Fellow AIAA
} 
3D textile architectures will be examined, and results will be compared against each another to determine their response and the effect of hybridization on the observed failure mode.

\section{Material}

3DWC are similar to other woven composites, however instead of only having in-plane weaving, through the thickness reinforcement is provided. A small number of fiber tows is used to provide reinforcement, binding all of the layers together, while the remaining fiber tow bundles are restricted to in-plane movement. The in-plane warp and weft fibers are straighter than a 2D woven composite. Details of the material have been discussed previously. ${ }^{7}$ A simplified idealized version of $3 \mathrm{D}$ weaving can be seen in figure 1 . Where the warp and weft fibers are represented by the blue and red geometry respectively, while the Z-Fiber is represented by the yellow fiber. Many different configurations can be created by varying the amount of Z-fiber used along with the details of how the Z-fiber moves between the layers.

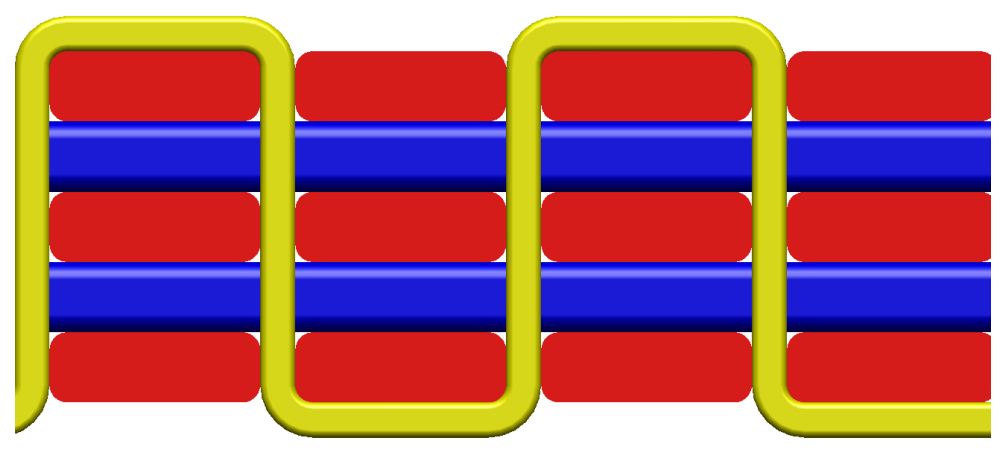

Figure 1. The yellow color path represents the course that the Z-fiber follows during the weaving process. ${ }^{7}$

In this investigation eight different architectures have been investigated to determine their hybridized mechanical performance characterized by the compressive/shear response. A baseline material is used which has the same 3D woven architecture as the hybrid panels, but uses only S2 glass material. The next material has the same configuration except uses IM7 carbon for the warp and weft tows, with an S2 glass fiber for the Z-fiber material. 2D Woven Kevlar material has also been tested to understand the response of the Kevlar material to shear. Due to Kevlar's superior fiber properties it was investigated as a replacement for Z-Fibers. Therefore a material was created using S2 glass warp and weft fibers with the Z-fiber being woven with Kevlar. Finally fully hybrid architectures were examined. The first hybrid architecture was an un-symmetric architecture that features two layers of carbon fiber in both the warp and weft directions with the remainder being glass layers. The Z-fiber was made of Kevlar fibers and this material was examined in two different thicknesses. A symmetric material was also created which resembles a "Sandwich Panel" since there are effectively face sheets of carbon with the core being made of S2 glass. A final architecture of a functionally graded material was investigated using diminishing amounts of carbon fiber in the material. Details of some of the architectures can be seen in 2. These materials were previously tested in tension as discussed by Pankow et. al. ${ }^{7}$

The dry 3D woven preforms were infused inhouse using a VARTM process. The matrix material chosen was SC-15 polymer matrix. Individual material properties for each constituent are provided in table 1 as a reference.

As discussed previously, macroscopic images of some samples after resin infusion can be seen in figure

The word "fiber" will be used to refer to fiber tows and fibers, interchangeably. The context is clear from the sentence when used. 
Table 1. Material Characteristics for fibers and matrix used.

\begin{tabular}{ccccccc} 
& $\begin{array}{c}E_{1} \\
\mathrm{msi}\end{array}$ & $\begin{array}{c}E_{2} \\
\mathrm{msi}\end{array}$ & $\begin{array}{c}\nu_{12} \\
-\end{array}$ & $\begin{array}{c}\nu_{23} \\
-\end{array}$ & $\begin{array}{c}G_{12} \\
\mathrm{msi}\end{array}$ & $\begin{array}{c}G_{23} \\
\mathrm{msi}\end{array}$ \\
\hline Carbon & 40.03 & 2.50 & 0.2 & 0.25 & 2.70 & 0.70 \\
\hline Glass & 16.56 & 16.56 & 0.22 & 0.22 & 6.74 & 6.74 \\
\hline Kevlar & 16.24 & 16.24 & 0.36 & 0.36 & 8.12 & 8.12 \\
\hline SC-15 & 0.360 & & 0.35 & & & \\
\hline
\end{tabular}

3. Some of the samples show that there are visible voids within the material. These could be found to be sources of failure initiation. Void content measurements were made using density measurements and fiber matrix burn out to show that the overall void content is under $2 \%$. However it should be noted that these techniques do not work on the hybrid materials and classification of voids can be accomplished through the use of CT scan reconstruction.

Table 2. Architecture thicknesses and layer breakdown. The functionally graded sample is based on effective carbon layers

\begin{tabular}{ccccc} 
& Thickness (in) & \# of Layers & \# of Carbon Layers & \% Carbon \\
\hline Baseline & 0.340 & 9 & 0 & 0 \\
\hline Carbon & 0.340 & 9 & 9 & 100 \\
\hline Kevlar Z-fiber & 0.650 & 17 & 0 & 0 \\
\hline Thin Unsymmetric & 0.346 & 9 & 4 & 44.5 \\
\hline Thick Unsymmetric & 0.659 & 17 & 4 & 23.5 \\
\hline Thick Symmetric & 0.626 & 17 & 8 & 47.0 \\
\hline Functionally Graded & 0.649 & 17 & 7 & 41.2 \\
\hline
\end{tabular}




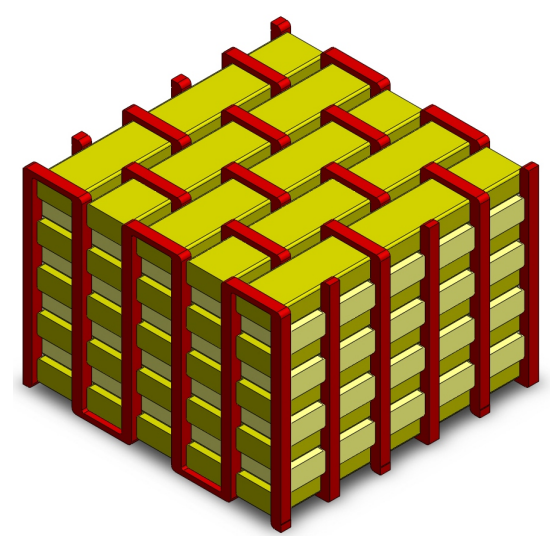

(a) Baseline architecture - The Z-fiber for these samples is also glass, but shown as kevlar to differentiate it from the rest of the glass fiber tow bundles.

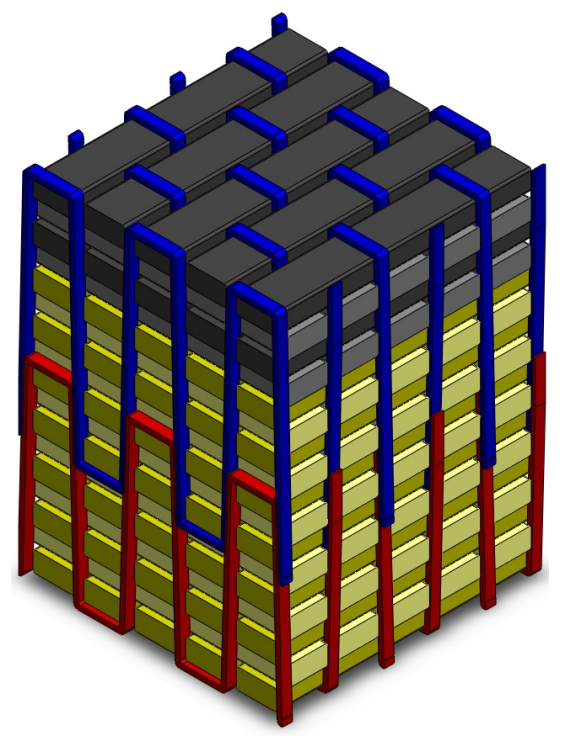

(c) Thick Unsymmetric

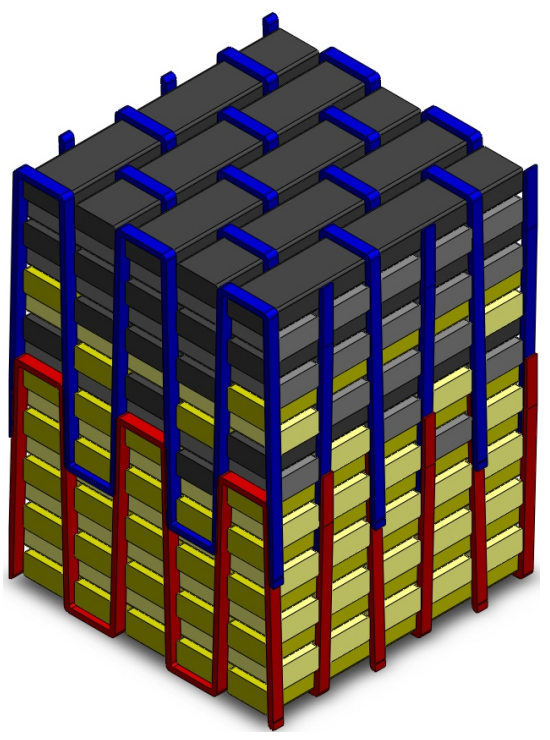

(e) Functionally Graded

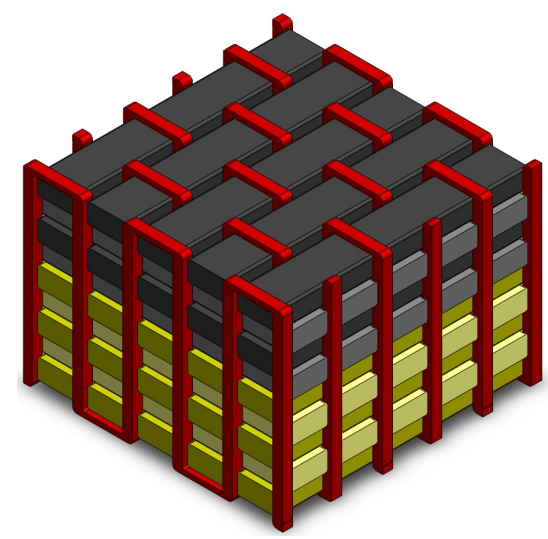

(b) Thin Unsymmetric

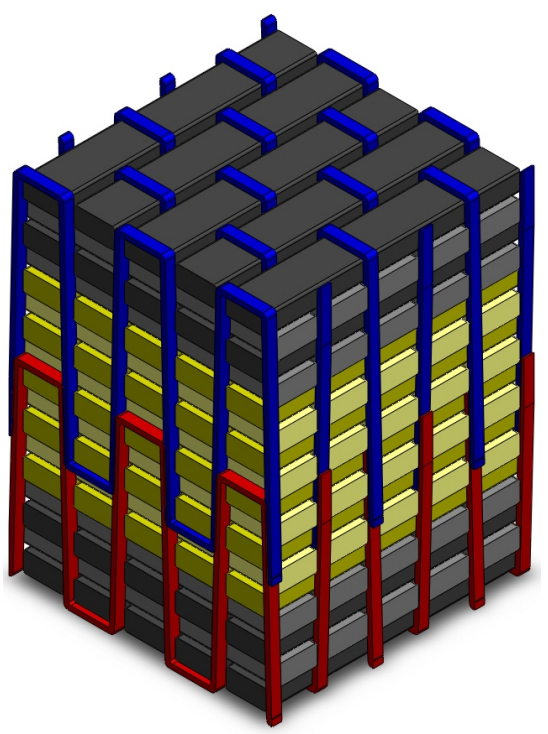

(d) Thick Symmetric
Carbon

\section{Glass}

Kevlar

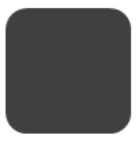

(f)

Figure 2. H3DWC architectures investigated ${ }^{7}$ 


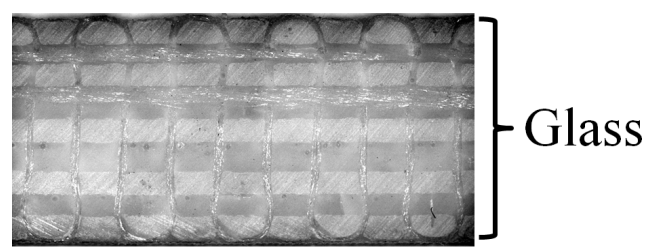

(a) Baseline

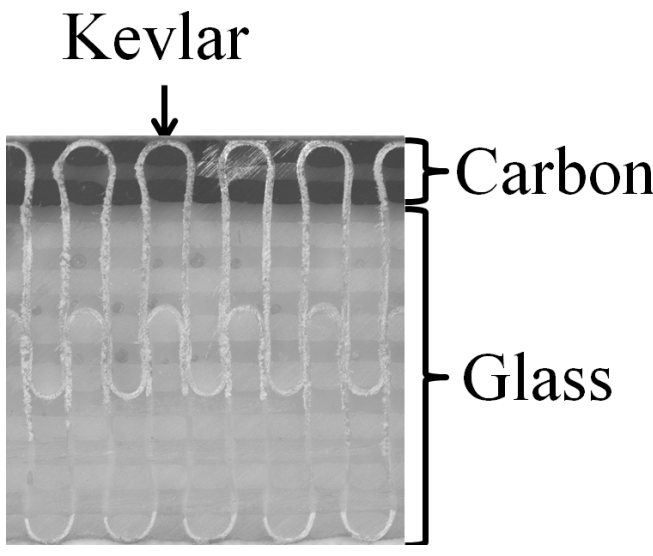

(c) Thick Unsymmetric

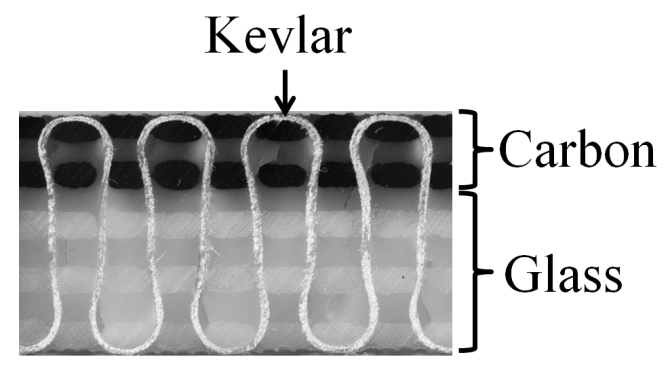

(b) Thin Unsymmetric

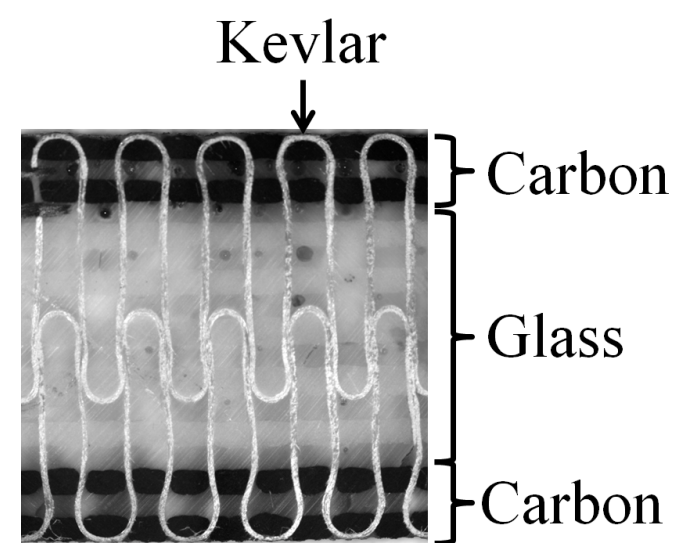

(d) Thick Symmetric

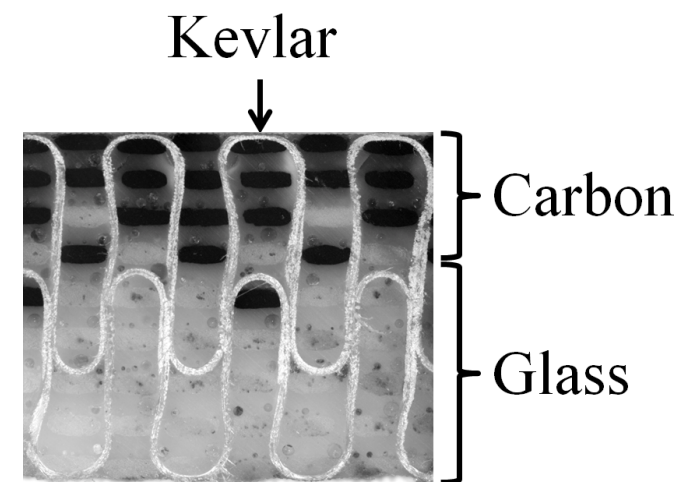

(e) Functionally Graded

Figure 3. Polished surfaces of $3 \mathrm{D}$ woven samples after resin infusion. ${ }^{7}$ 


\section{Laterally Constrained Compression Test}

Traditional compression tests do not simulate how material within a loaded, larger panel will behave. A different test must be performed to simulate the confinement from other parts of the panel material when subjected to localized penetration. In order to simulate this better, a sample is loaded through the thickness in compression. However, additional constraints have been added to prevent Poisson's expansion in one of the two in-plane directions. Figure 4 shows the test fixture and the loading direction, with confinement. This test has previously been discussed by Yen, ${ }^{8}$ however, some relevant details will discussed here.

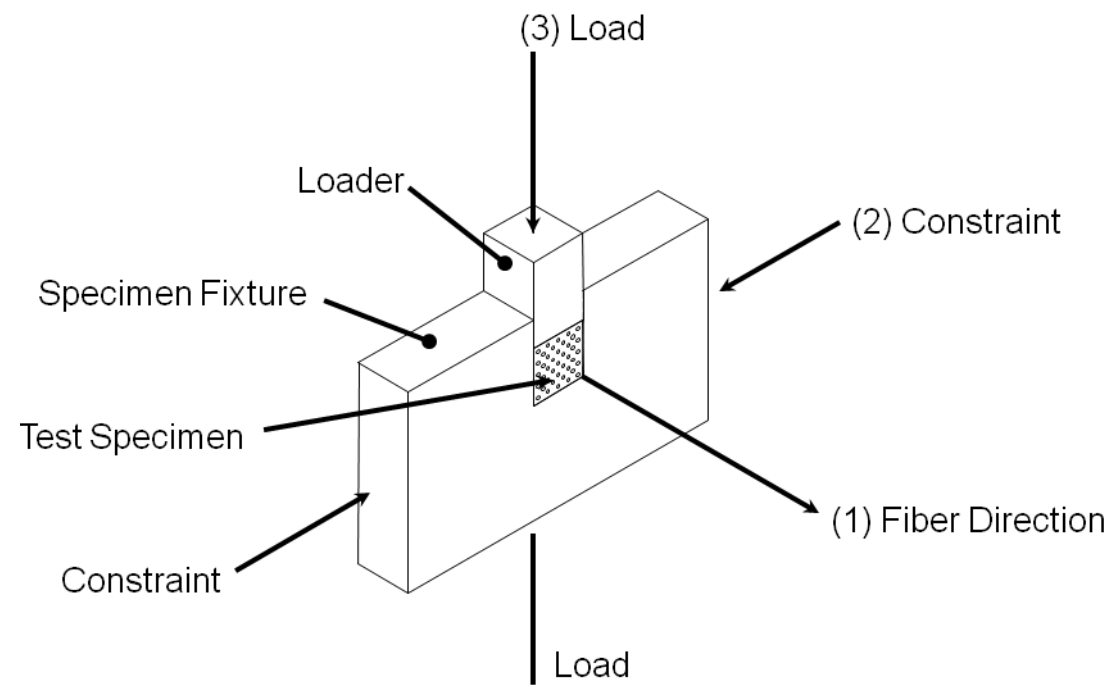

Figure 4. The laterally constrained compression tests setup on a unidirectional material.

When the specimen is loaded until failure, a sliding shear plane will form where failure occurs in the material. This plane occurs at an angle $\theta$ with the surface of the material, see figure 5 . In this case the nominal stress, $\left(S_{F C}\right)$, can be defined as,

$$
S_{F C}=\frac{F_{\max }}{A}
$$

where, $F_{\max }$ is the maximum force and $A$ is the cross sectional area. Using these results and the known angle that is formed at the failure surface, Mohr's circle can be used to calculate the normal and shear stresses acting on the surface of the failure plane. These stresses are computed as,

$$
\begin{gathered}
S_{N}=S_{F C} \cos ^{2} \theta \\
S_{N F S}=\frac{1}{2} S_{F C} \sin 2 \theta
\end{gathered}
$$

where $S_{N F S}$ and $S_{N}$ are shear and compressive normal stresses, respectively. These results are dependent upon the fact that the two principal stresses are $S_{F C}$ and 0 . The compressive stress in the orthogonal direction does not affect these results as the failure does not lie in that plane. The normal stress acting on the fiber shear-failure plane and the macroscopic shear sliding strength involved at fiber failure can be combined using a Mohr-Coulomb criterion as follows,

$$
\begin{gathered}
S_{F S}=S_{N F S}+\mu S_{N} \\
\mu=\tan \phi \\
\phi=90^{\circ}-2 \theta
\end{gathered}
$$

where $\mu$ is a constant similar to the coefficient of friction and $\phi$ is the frictional angle. $S_{N F S}$ is the cohesive shear strength and represents the level of shear strength in the absence of any normal stress acting on the shear-failure plane or in the frictionless, $\mu=0$, case. 


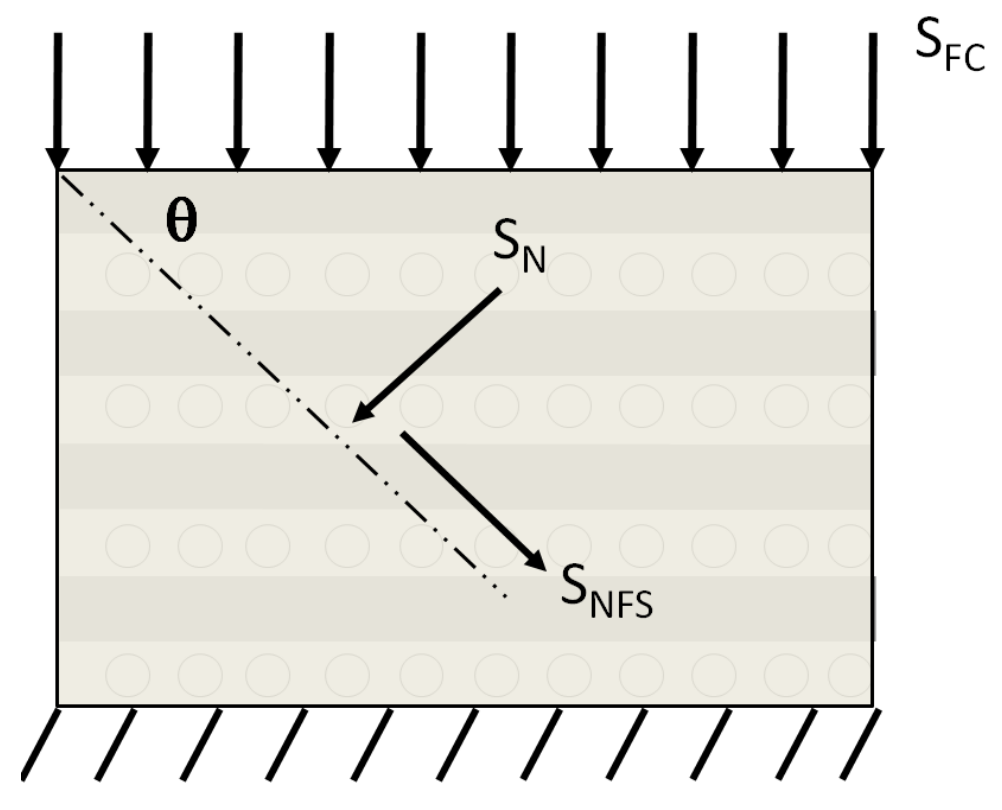

Figure 5. The shear failure plane of the fiber tows under constrained compression. 


\section{Hybrid Data}

All eight architectures were tested in the two main material orientations, warp and weft. These orientations are orthogonal to each other since the material is orthogonally woven. The effective nominal stress at failure (crush stress) is presented in table 3 for the warp direction and table 4 for the weft. The material was then shown to be normalized using the all glass 3D woven panel as the baseline configuration. The crush strength baseline material is about $90 \mathrm{ksi}$ for both orientations. The carbon panel showed a slight increase in strength even though the material is weaker in the transverse direction. This could be benefited by the glass Z-fiber that is in the material. The 2D woven Kevlar material proved to be the highest strength of all the materials tested. This shows it has good resistance to shear. However, like the carbon the material, it is not isotropic and shows different response through the thickness. By simply changing the Z-fiber material in the all glass panel, a reduction of $20 \%$ in the strength of the material is observed. This is significant because the Kevlar performed well, however, it was not in a Z-fiber role in the tests presented here. This is a very interesting result that will be discussed later. The other hybrid materials seemed to show a similar trend in strength. All showed a 15\%-20\% reduction in strength. Since these all have Kevlar Z-fibers this reduction is likely a results from this material and not the other hybridization seen between the glass and Kevlar. The Functionally graded material ashows the worst performance out of all the materials tested. It showed a reduction of 30\%-35\% in strength. This result will also be examined further.

Table 3. Nominal Stress in Warp Direction

\begin{tabular}{cccc}
\hline & $\begin{array}{c}\text { Effective Stress } \\
\text { ksi }\end{array}$ & $\begin{array}{c}\text { Standard Deviation } \\
\text { ksi }\end{array}$ & Normalized \\
\hline Baseline & 93.0 & 3.9 & 1 \\
\hline Carbon & 105.9 & 5.3 & 1.14 \\
\hline 2D Woven Kevlar & 136.5 & 4.5 & 1.47 \\
\hline Glass Kevlar Z-Fiber & 76.5 & 2.9 & 0.82 \\
\hline Thin Unsymmetric & 79.1 & 4.4 & 0.85 \\
\hline Thick Unsymmetric & 74.0 & 3.3 & 0.80 \\
\hline Functionally Graded & 66.6 & 4.2 & 0.72 \\
\hline Symmetric & 84.4 & 1.9 & 0.91 \\
\hline
\end{tabular}

Table 4. Nominal Stress in Weft Direction

\begin{tabular}{cccc}
\hline & $\begin{array}{c}\text { Effective Stress } \\
\mathrm{ksi}\end{array}$ & $\begin{array}{c}\text { Standard Deviation } \\
\mathrm{ksi}\end{array}$ & Normalized \\
\hline Baseline & 89.5 & 7.6 & 1 \\
\hline Carbon & 98.9 & 9.1 & 1.11 \\
\hline 2D Woven Kevlar & 136.5 & 4.5 & 1.53 \\
\hline Glass Kevlar Z-Fiber & 77.6 & 4.5 & 0.87 \\
\hline Thin Unsymmetric & 84.2 & 0.6 & 0.94 \\
\hline Thick Unsymmetric & 78.4 & 6.3 & 0.88 \\
\hline Functionally Graded & 58.5 & 3.2 & 0.65 \\
\hline Symmetric & 82.6 & 8.5 & 0.92 \\
\hline
\end{tabular}


To get a better understanding for some of the reasons for the reduction in strength, images of the fracture surface have been examined. Figures 6 and 7 show the failed surfaces for the different architectures. The majority of samples form a shear band that appears on the surface of the material. However the pure carbon material did not show this failure. The pure carbon sample showed crushing of the layers. Additionally the functionally graded material failed with tow push out from the hybrid layers where it was part carbon and part Kevlar. Examining the unsymmetric and symmetric materials further shows that shear band formation never occurs in the carbon layers of the material. The shear band always forms in the glass layers and hardly propagates into the carbon where a change in angle is observed or it does not even enter the carbon layers. This is likely because the strength of the carbon layers are higher than the strength of the glass as shown in tables 3 and 4 . The glass layers appear to be the weak link in these materials with all of the failure occurring in these layers. The functionally graded architecture aimed to eliminate this, however grading has altered the failure modes and resulted in reduced strength. There seems to be a competition between the carbon and glass layers pushing against each other preventing a shear band from forming in the material.

The fiber punch shear strength can be computed from the measured crush strength using equations 2 and 3. This, however, requires the measurement of the angle of the shear band failure from the tested specimen. Average angles and the computed shear and compressive normal stresses for each material system are presented in tables 5 and 6 in warp and weft directions, respectively. It can be seen in these tables that the warp direction consistently showed a larger shear angle than seen in the weft orientation. Most of the configurations showed that the shear angle formed was similar to that seen in the baseline all glass sample. Due to the weakest link, the failure usually initiated in the glass region and provided the failure angle. Evidently from tables 5 and 6 , the punch shear strengths measured from the thin-unsymmetric, thickunsymmetric and symmetric hybrid specimens match reasonably well with that of the baseline configuration. The functionally graded specimens showed no shear bands at failure, instead localized failure caused by confinement of interwoven carbon and Kevlar tows.

Table 5. Punch Shear Stress in Warp Direction

\begin{tabular}{ccccc}
\hline & $\begin{array}{c}\text { Shear Angle } \\
\mathrm{deg}\end{array}$ & $\begin{array}{c}\text { Standard Deviation } \\
\mathrm{deg}\end{array}$ & $\begin{array}{c}\text { Normal Stress } \\
\mathrm{ksi}\end{array}$ & $\begin{array}{c}\text { Shear Stress } \\
\mathrm{ksi}\end{array}$ \\
\hline Baseline & 37.5 & 3.8 & 66 & 41 \\
\hline Carbon & $\mathrm{N} / \mathrm{A}$ & $\mathrm{N} / \mathrm{A}$ & $\mathrm{N} / \mathrm{A}$ & $\mathrm{N} / \mathrm{A}$ \\
\hline 2D Woven Kevlar & 30.1 & 3.8 & 102 & 59 \\
\hline Glass Kevlar Z-Fiber & 39.2 & 5.0 & 46 & 37 \\
\hline Thin Unsymmetric & 45.3 & 6.4 & 39 & 39 \\
\hline Thick Unsymmetric & 38.2 & 3.3 & 46 & 36 \\
\hline Functionally Graded & $\mathrm{N} / \mathrm{A}$ & $\mathrm{N} / \mathrm{A}$ & $\mathrm{N} / \mathrm{A}$ & $\mathrm{N} / \mathrm{A}$ \\
\hline Symmetric & 39.0 & 5.1 & 51 & 41 \\
\hline
\end{tabular}

The experimental results suggest that the inclusion of the Kevlar Z-fiber produces a weaker response in these materials. If one examines the fiber volume fractions of the individual constituents, see figure 8, one notices that the carbon and glass have similar fiber volume fractions around 56\%-60\%. The Kevlar fibers on the other hand have a much higher fiber volume fraction. Closer examination of the figure shows that the Kevlar fibers are deforming. They are no longer circular and deformation is observed where two adjacent fibers come in contact. In the $2 \mathrm{D}$ woven material, elevated strength was observed, but this could be due to a high fiber volume fraction and additionally mainly the material experiences transverse compression. When the Kevlar is loaded with high amounts of shear it seems to fail prematurely, acting almost like a stress concentration in the material. All of the 3D woven materials with Kevlar Z-fiber show premature failure.

In future studies, 2D woven material will be examined to look at the effect of hybridization and help further understand the results that have been obtained. Additionally further quasi-static and dynamic testing is being pursued to verify the results that are obtained from the confined compression testing. 
Table 6. Punch Shear Stress in Weft Direction

\begin{tabular}{ccccc}
\hline & $\begin{array}{c}\text { Shear Angle } \\
\mathrm{deg}\end{array}$ & $\begin{array}{c}\text { Standard Deviation } \\
\mathrm{deg}\end{array}$ & $\begin{array}{c}\text { Normal Stress } \\
\mathrm{ksi}\end{array}$ & $\begin{array}{c}\text { Shear Stress } \\
\mathrm{ksi}\end{array}$ \\
\hline Baseline & 32.1 & 3.5 & 56 & 43 \\
\hline Carbon & $\mathrm{N} / \mathrm{A}$ & $\mathrm{N} / \mathrm{A}$ & $\mathrm{N} / \mathrm{A}$ & $\mathrm{N} / \mathrm{A}$ \\
\hline 2D Woven Kevlar & 30.1 & 3.8 & 102 & 59 \\
\hline Glass Kevlar Z-Fiber & 35.9 & 3.9 & 51 & 37 \\
\hline Thin Unsymmetric & 31.0 & 3.0 & 62 & 37 \\
\hline Thick Unsymmetric & 32.2 & 3.5 & 56 & 35 \\
\hline Functionally Graded & $\mathrm{N} / \mathrm{A}$ & $\mathrm{N} / \mathrm{A}$ & $\mathrm{N} / \mathrm{A}$ & $\mathrm{N} / \mathrm{A}$ \\
\hline Symmetric & 38.5 & 7.9 & 50 & 39 \\
\hline
\end{tabular}




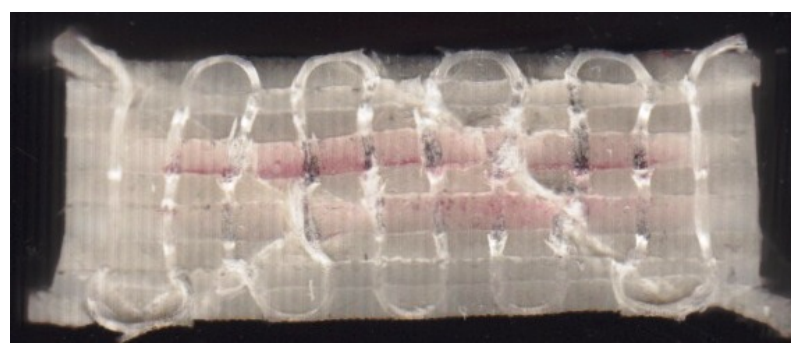

(a) Baseline

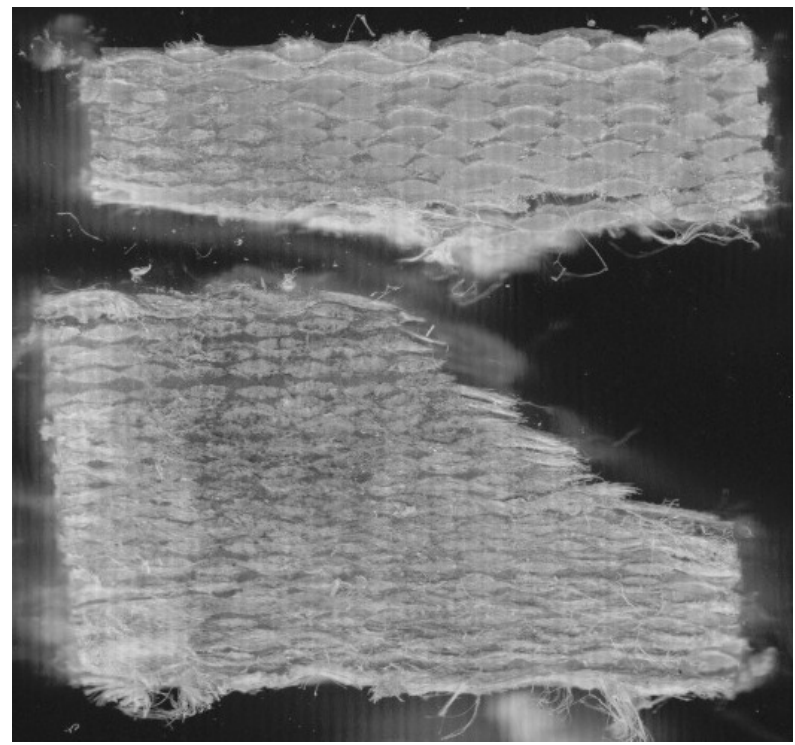

(c) 2D Kevlar

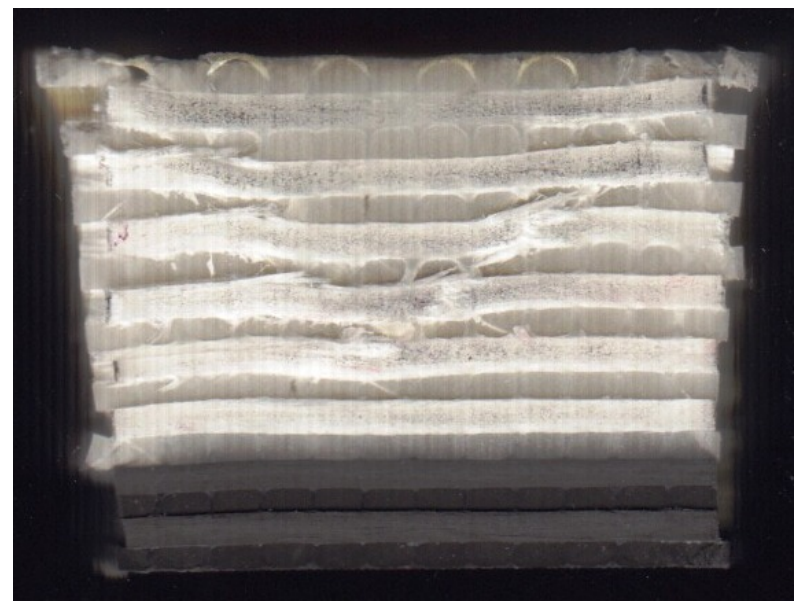

(e) Thick Unsymmetric

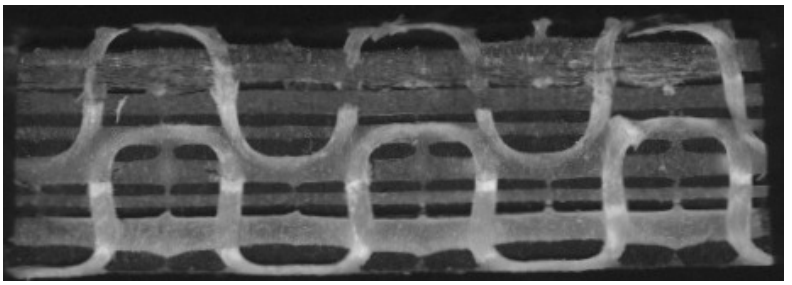

(b) Carbon

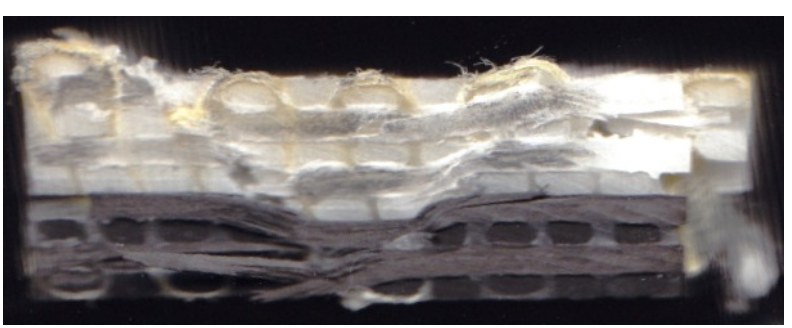

(d) Thin Unsymmetric

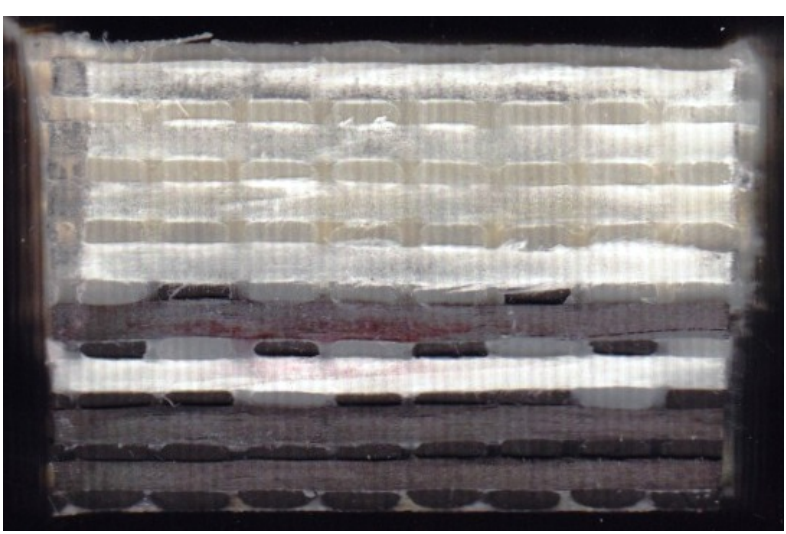

(f) Functionally Graded

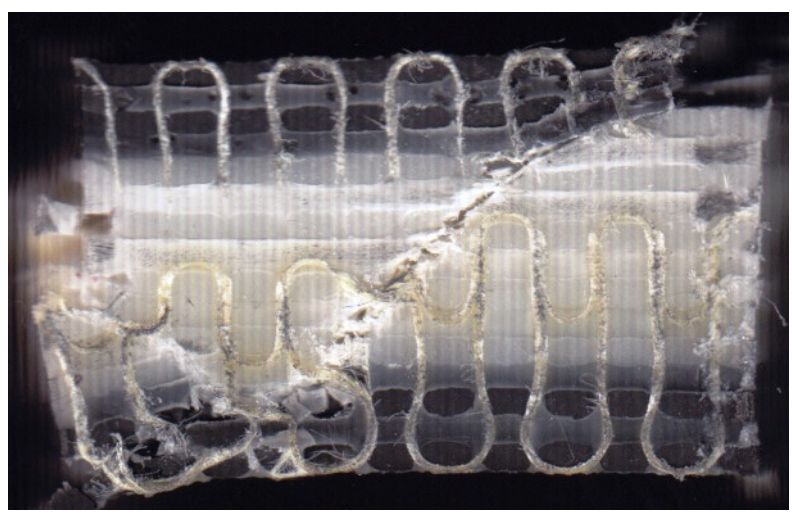

(g) Simmetric 


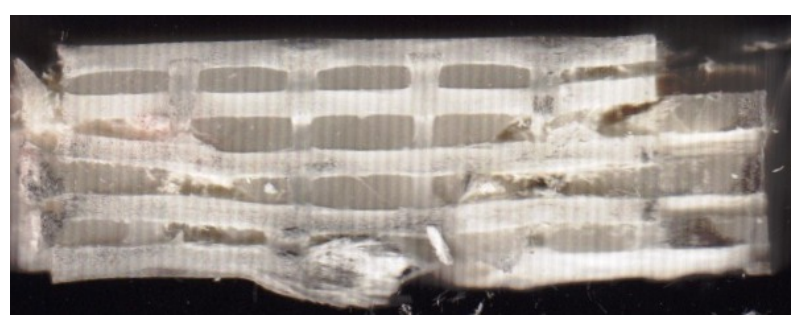

(a) Baseline

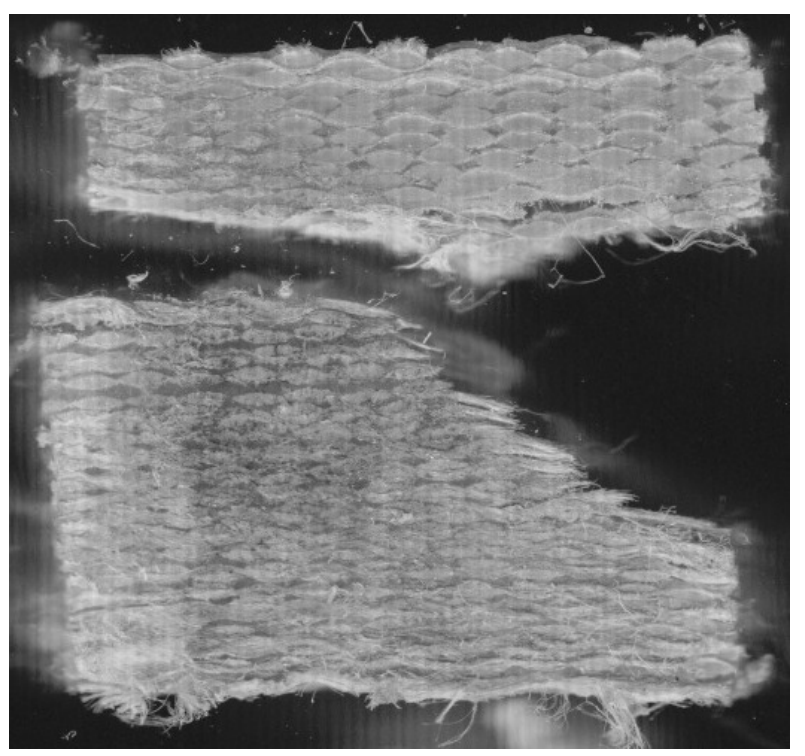

(c) 2D Kevlar

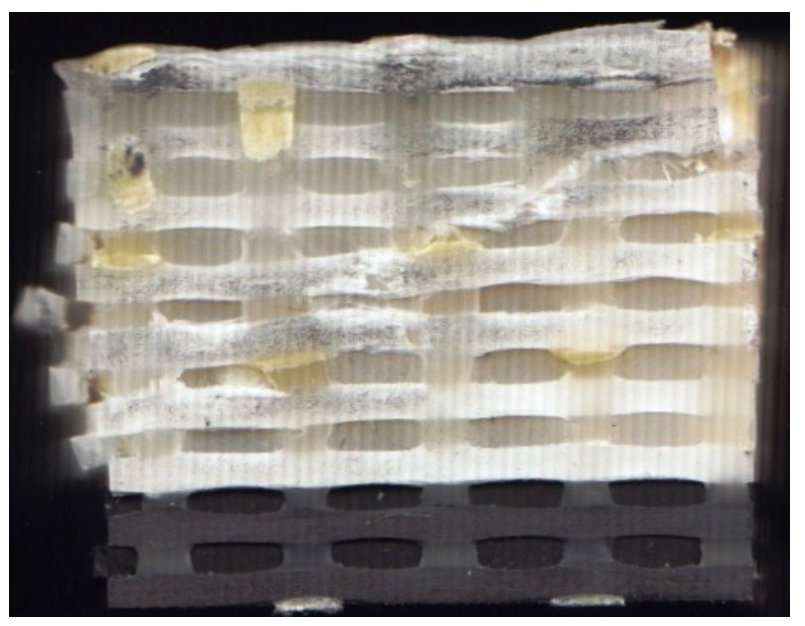

(e) Thick Unsymmetric

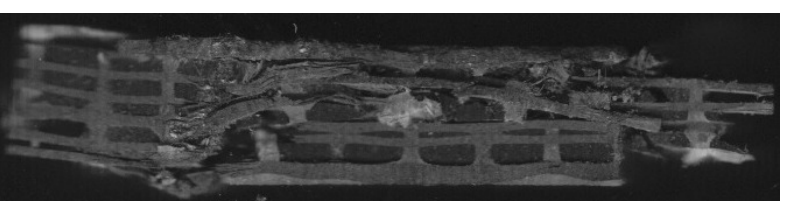

(b) Carbon

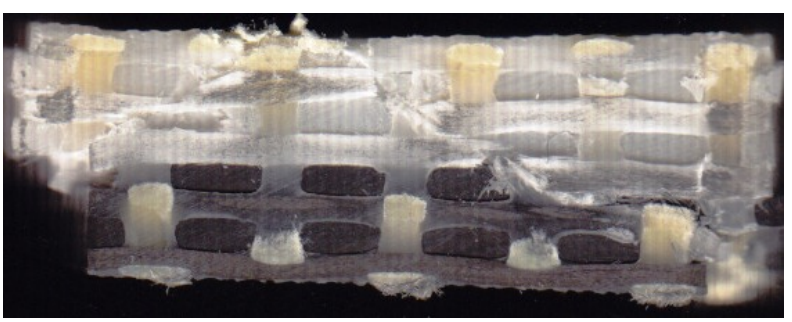

(d) Thin Unsymmetric

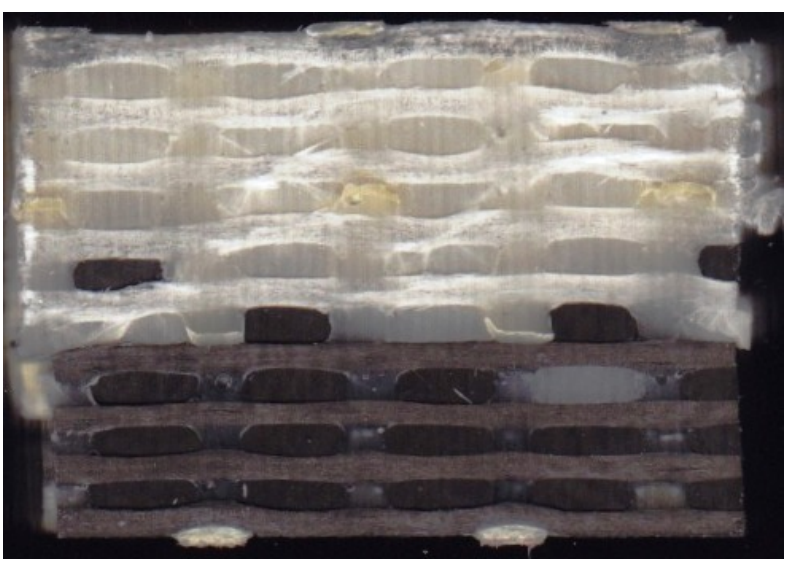

(f) Functionally Graded

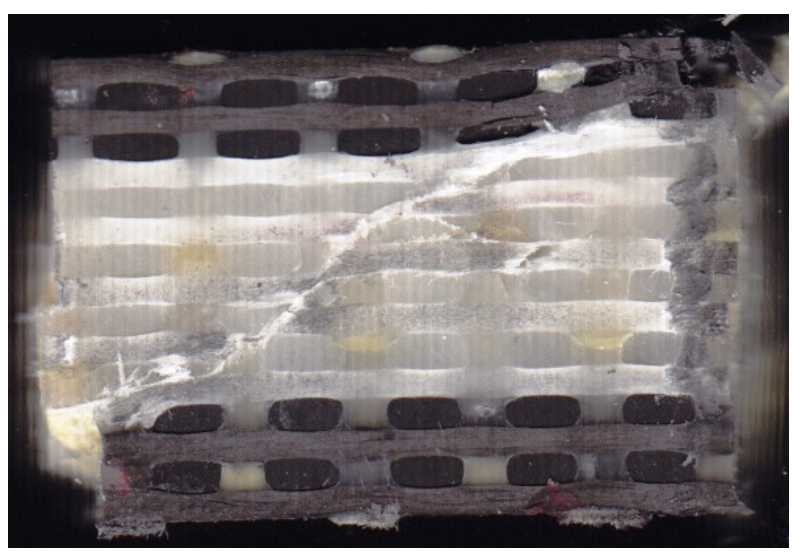

(g) \$2nofindeltric

American Institute of Aeronautics and Astronautics 


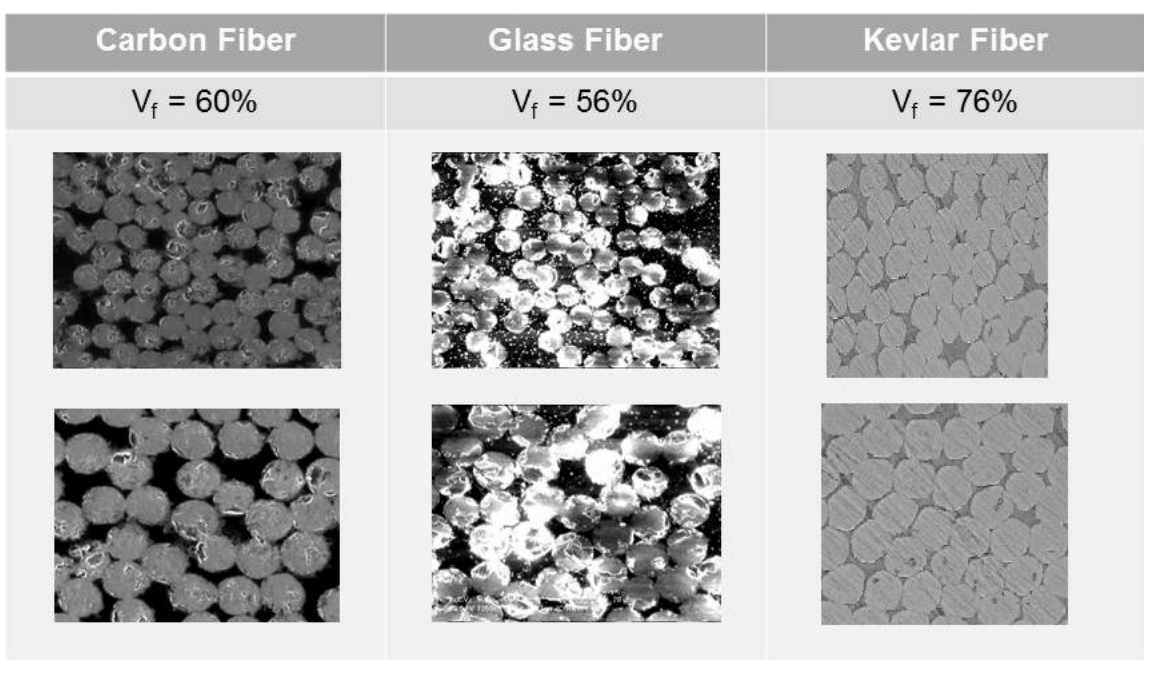

Figure 8. Computed fiber volume fractions for individual materials after infusion. 


\section{Conclusion}

Through-the-thickness confined compression test results revealed some interesting trends in the failure mode of hybridized 3D woven composites. Although the individual components (carbon tows, glass tows and kevlar tows) would suggest that there would be an increase in effective strength in these materials, hybridized fiber architectures show significant effect on the measured nominal failure response of the materials. In the symmetric and unsymmetric hybrid materials we get similar failure modes occurring in the glass layer which is the weakest layer from individual testing. The functionally graded material does not have a clear transition, rather each layer has a mixture of tows (carbon and glass) that the interaction of those tows has localized the fiber/matrix failure, preventing the formation of a major shear band. Failure in these materials was seen to be similar to that occurring at high loading rates. The study indicates that the use of kevlar as Z-Fiber may not produce the results predicted based on mechanical properties of fibers. Further work is ongoing in this investigation to understand the performance of these materials.

\section{Acknowledgments}

The authors would like to thank the Army Research Laboratory for their continued financial support.

\section{References}

${ }^{1} \mathrm{M}$. Guden, U. Yildirim, I. Hall, Effect of strain rate on the compression behavior of a woven glass fiber/sc-15 composite, Polymer Testing 23 (6) (2004) 719 - 725. doi:10.1016/j.polymertesting.2004.01.004.

URL http://www.sciencedirect.com/science/article/pii/S0142941804000091

${ }^{2}$ B. Song, W. Chen, T. Weerasooriya, Quasi-static and dynamic compressive behaviors of a s-2 glass/sc15 composite, Journal of Composite Materials 37 (19) (2003) 1723-1743. arXiv:http://jcm.sagepub.com/content/37/19/1723.full.pdf+html, doi:10.1177/002199803035189.

URL http://jcm.sagepub.com/content/37/19/1723.abstract

${ }^{3}$ Y. Sun, G. Wang, Compressive response of uhmwpe/vinyl ester $3 \mathrm{~d}$ orthogonal woven composites at high strain rates, Advance Materials Research 97-101 (2010) 522-525.

${ }^{4}$ M. Pankow, A. Salvi, A. Waas, C. Yen, S. Ghiorse, Split hopkinson pressure bar testing of 3d woven composites, Composites Science and Technology 71 (9) (2011) 1196 - 1208. doi:10.1016/j.compscitech.2011.03.017.

URL http://www.sciencedirect.com/science/article/pii/S0266353811001199

${ }^{5}$ J. G. Jr., B. Gama, C. Cichanowski, J. Xiao, Interlaminar shear strength of plain weave s2-glass/sc79 composites subjected to out-of-plane high strain rate compressive loadings, Composites Science and Technology 65 (1112) (2005) $1891-1908$. doi:10.1016/j.compscitech.2005.04.006.

URL http://www.sciencedirect.com/science/article/pii/S0266353805000904

${ }^{6}$ A. Manzella, B. Gama, J. G. Jr., Effect of punch and specimen dimensions on the confined compression behavior of s-2 glass/epoxy composites, Composite Structures 93 (7) (2011) 1726 - 1737. doi:10.1016/j.compstruct.2010.11.006.

URL http://www.sciencedirect.com/science/article/pii/S0263822310003806

${ }^{7}$ M. Pankow, C. Yen, M. Rudolph, B. Justusson, D. Zhang, A. Waas, Experimental investigation on the deformation response of hybrid 3d woven composites, in: 53rd AIAA/ASME/ASCE/AHS/ASC Structures, Structural Dynamics and Materials Conference, AIAA, 2012.

${ }^{8}$ C.-F. Yen, A ballistic material model for continuous-fiber reinforced composites, International Journal of Impact Engineering 46 (0) (2012) $11-22$. doi:10.1016/j.ijimpeng.2011.12.007.

URL http://www.sciencedirect.com/science/article/pii/S0734743X11002041 